\title{
Stop, reflect, replace Renovating our foundation for inclusive participation
}

A $s$ in many academic libraries all over the country, attracting and retaining people of color has been a continuous, uphill battle."

"It is a troubling reality that our current librarian ranks do not represent the communities served by libraries."

Sadly, both of these statements, from 2001 and 2003, still hold true today. Sustained attempts to lower barriers for BIPOC (Black, Indigenous, and People of Color), such as through residency programs, have not resulted in their long-term retention, and white librarians still make up the vast majority of degreed librarians. Now is the time to stop this cycle and change the narrative in academic librarianship.

The lack of representation is indicative of deeper structural inequalities pervasive in U.S. institutions, the resulting racial disparities of which are being blatantly exposed in the current global pandemic and economic crises. Work life has been upended, and those among us privileged to still be employed and in good health are confronted with a workplace in flux. Due to the pandemic, academic librarians needed to pivot services mid-semester to virtual-only services. During the fall term, the change has been to a hybrid model of library services with the necessity of a quick shift back to virtual-only services as a possibility at any moment, should COVID-19 cases increase. At the same time, the Black Lives Matter movement has gained support on a global scale. Organizations are issuing statements in support of racial equity, while mass protests are being held to demand racial justice. Let's use this momentum of change to disrupt our own behavior that is contributing to supporting structural inequality in our institutions. Reading antiracist literature and putting together diversity committees alone won't change our behavior. We must additionally commit to replacing the underlining structural foundation with an inclusive framework paired with an ongoing focus on an openness to learning and self-reflection, the latter of which is a central factor of "cognitive flexibility," which can reduce resistance to organizational change. ${ }^{3}$ And change we must. Failing this, we will continue ingrained behavioral patterns that shut out diverse perspectives.

\section{Self-reflection, implicit biases, and learning}

Too often throughout the workday, we quickly go through emails and rush from one deadline to the next without incorporating self-reflection into our work. The absence of reflection leaves us operating on an automatic basis, propelled forward in part by numerous implicit biases. While we may consciously try to project we are open to learning and are proponents of fair treatment for all, our actions likely tell a different story because people generally hold implicit biases against that which is differentother people as well as ideas.

Aubrey Iglesias is cataloging librarian at the New Mexico State University Library, email: aiglesia@nmsu.edu

C 2020 Aubrey Iglesias 
The low number of academic librarians who are BIPOC can partially be attributed to intergroup bias. Intergroup bias basically is the wariness of (and sometimes feeling threatened by) people we socially categorize as belonging to another group (such as to another race), whereas we are drawn to people we perceive as being a member of our own group. This is a concern because the inclusion of diverse voices is an essential component of learning. For libraries to truly become learning organizations, the input from people from diverse backgrounds and experiences helps us question assumptions and find solutions to issues, which we may not have been aware existed. The potential breadth and depth of everyone's learning are diminished without the participation of a diverse library workforce complete with authentic interactions between people of different backgrounds.

Other implicit biases further point to our general inclination to not be open to changing and therefore not fully engaging in antiracist behavior, which could enact significant changes in our organizations, including increased representation of BIPOC in professional roles in academic libraries. We say we want to be innovative; however, there is a creativity bias in higher education. Creative ideas need to be both novel and useful. The more novel an idea is though, the higher the uncertainty becomes for an evaluator to determine if the idea is useful to implement. Because people are motivated to avoid the state of uncertainty, novel ideas are frequently rejected. ${ }^{4}$ While the status quo bias is the "tendency for 'doing nothing or maintaining one's current or previous decision," "' the biases for existence ("people treat the mere existence of something as evidence of its goodness [...] an existing state is evaluated more favorably than an alternative") 6 and longevity ("the longer something is thought to exist, the better and more right it is judged to be" $)^{7}$ promote the status quo. ${ }^{8}$ Furthermore, egalitarianism requires mental effort whereas hierarchy is valued quickly. Even individuals proclaiming to hold egalitarian values fall back on making decisions of a hierarchical nature when they are distracted or have to make a quick decision. ${ }^{?}$ Adequate time to reflect expands our potential to explore alternative ways of doing our work (and with whom we partner) and enables us to make decisions that are more inclusive, such as decisions that lead to more equitable outcomes.

Some of us may be falsely under the impression that we are unable to learn certain subject matters and thus unintentionally hold colleagues and ourselves back from learning and changing how we do our work. We may make unmerited judgements about the capabilities of our colleagues, including our paraprofessional team members, which impede their progress and stifle their contributions to organizational change. However, scientific research confirms everyone is capable of learning-able to change, grow, adapt, and rewire their brains. We can furthermore unlock learning. ${ }^{10}$ Understanding how the brain works can empower us to embrace deep learning, even in subjects we previously believed were too difficult for us, and encourage our colleagues in their growth.

\section{A new foundational grounding}

Higher education traditionally rewards individualism and was created to support a white, male-dominated world. In LIS literature, academia is documented as being perceived as an unwelcoming, even at times hostile, environment by some BIPOC. ${ }^{11}$ Relational-cultural theory (RCT), which has its origins in counseling, provides an alternative framework with growth-fostering relationships at its core. In RCT, "individuals approach optimal development while participating in relationships characterized by authenticity, relational connection, mutuality, and engagement."12 The emphasis is on creating and sustaining authentic relationships, collaborating with others, and sharing the workload. ${ }^{13}$ This framework aligns well with the keys to unlocking learning, which place an importance on collaboration.

Now is the time to get out of business as usual by replacing stagnant behavior that upholds the status quo with an openness to learning and incorporating a self-reflection modus operandi into our decision making so that we are actively engaged in antiracist behavior. Interacting with colleagues within the RCT framework as a replacement to a strict hierarchical model in the 
academic library workplace will furthermore help us create more equitable environments open to welcoming diverse perspectives and transforming our practices. On this foundation, we will collectively imagine services truly pertinent to supporting and engaging with the diverse populations we serve. Now is the time.

\section{Notes}

1. Ninfa Trejo and Elaina Norlin, "Recruitment and Retention Project Team: Opportunities and Outcomes," CERL News 62, no. 5 (2001): 528, accessed July 10, 2020, https://crln.acrl.org /index.php/crlnews/article/view/19389/22689.

2. Harold Goss Jr., "The way I see it: Diversity: It's not just the right thing to do," CERL News 64, no. 9 (2003): 594, https://crln.acrl.org /index.php/crlnews/article/view/21145/26142.

3. Shao-Hsi Chung, Ying-Fang Su, and ShaoWen Su, "The Impact of Cognitive Flexibility on Resistance to Organizational Change," Social Behavior \& Personality: An International Journal 40, no. 5 (2012): 745, https://doi.org/10.2224/ sbp.2012.40.5.735.

4. Jennifer S. Mueller, Shimul Melwani, and Jack A. Goncalo, "The Bias against Creativity: Why People Desire but Reject Creative Ideas," Psychological Science 23, no. 1 (2012): 13, https:// doi.org/10.1177/0956797611421018. For mitigating creativity bias, see Jennifer Mueller, Creative Change: Why We Resist It... How We Can Embrace It (New York, NY: Mariner Books, 2018).

5. Scott Eidelman, Chris Crandall, and Jennifer Pattershall, "The Existence Bias," Journal of Personality and Social Psychology 97, no. 5 (2009): 765, https://doi.org/10.1037/a0017058.

6. Ibid.

7. Scott Eidelman and Chris Crandall, "Chapter Two-The Intuitive Traditionalist: How Biases for Existence and Longevity Promote the Status Quo," in Advances in Experimental Social Psychology 50, edited by Mark Zanna and James Olson (Waltham, MA: Academic Press, 2014): 53, https://doi.org/10.1016/B978 -0-12-800284-1.00002-3.

\section{Ibid.}

9. Laura Van Berkel, Chris Crandall, Scott Eidelman, and John Blanchar, "Hierarchy, Dominance, and Deliberation: Egalitarian Values
Require Mental Effort," Personality \& Social Psychology Bulletin (2015): 1-15, https://doi. org/10.1177/0146167215591961.

10. Jo Boaler, Limitless Mind: Learn, Lead, and Live without Barriers (New York, NY: HarperOne. 2019).

11. See Jaena Alabi's scholarship on racial microaggressions in LIS, especially: "Racial Microaggressions in Academic Libraries: Results of a Survey of Minority and Non-minority Librarians," Journal of Academic Librarianship 41, no. 1 (2015): 47-53, https://doi.org/10.1016/j. acalib.2014.10.008 and "This Actually Happened': An Analysis of Librarians' Responses to a Survey about Racial Microaggressions," Journal of Library Administration 55, no. 3 (2015): 179-91, https://doi.org/10.1080/01930826. 2015.1034040. For the additional effects of workplace bullying experienced by racial minority academic librarians, see Shin Freedman and Dawn Vreven, "Workplace Incivility and Bullying in the Library: Perception or Reality?" College \& Research Libraries 77, no. 6 (2017): 727-48, https://crl.acrl.org/index.php/crl/article /view/16553/17999 and Kaetrena Davis Kendrick and Ione T. Damasco, "Low Morale in Ethnic and Racial Minority Academic Librarians: An Experiential Study," Library Trends 68, no.2 (Fall 2019): 174-212.

12. A. Stephen Lenz, "Relational-Cultural Theory: Fostering the Growth of a Paradigm through Empirical Research," Journal of Counseling E Development 94 (October 2016): 528, https:// doi.org/10.1002/jcad.12100.

13. See Veronica Arellano Douglas' scholarship on RCT in LIS, especially: Veronica Arellano Douglas, "Growth through Relationship: From Conversation to Research Project," The Librarian Parlor blog (May 2, 2018), accessed July 10, 2020, https://libparlor.com/2018/05/02/growth-through -relationship-from-conversation-to-researchproject/ and Veronica Arellano Douglas and Joanna Gadsby, "All Carrots, No Sticks: Relational Practice in Library Instruction Coordination," In the Library with the Lead Pipe (July 10, 2019), accessed July 5, 2020, http:// www.inthelibrarywiththeleadpipe.org/2019 /all-carrots-no-sticks-relational-practice-and -library-instruction-coordination/\#respond. $\neq 2$ 